http://jmscr.igmpublication.org/home/ ISSN (e)-2347-176x ISSN (p) 2455-0450

crossref DOI: https://dx.doi.org/10.18535/jmscr/v7i11.01

\author{
Journal Of Medical Science And Clinical Research \\ IGM Publication \\ An official Publication of IGM Publication
}

\title{
Original Research Article \\ A comparative study of Herniotomy versus Herniorrhaphy in adults with uncomplicated indirect Inguinal Hernia in a Teaching Hospital
}

\author{
Author
}

\section{Dr S Subhasini ${ }^{1^{*}}$}

Assistant Professor, Department of General Surgery, Rajiv Gandhi Institute of Medical Sciences, RIMS, Adilabad

*Corresponding Author

Dr S Subhasini

101, East Block, Vasavi Dreams, Street No 2, Czech Colony, Sanath Nagar, Hyderabad 500018, Telangana State

\begin{tabular}{l} 
Abstract \\
Surgical treatment of hernia is a very common procedure performed in the Department of general \\
surgery. The most commonly used methods of hernia repair are herniotomy, herniorrhaphy, and \\
hernioplasty each one has its advantages and disadvantages. We in the present study tried to compare \\
herniorrhaphy with herniotomy alone in young adult patients. \\
Methods: The present cross-sectional comparative study was carried in the Department of General \\
Surgery, Rajiv Gandhi Institute of Medical Sciences [RIMS] Adilabad. Based on the inclusion and \\
exclusion criteria during the study period, we identified a total of n=40 patients. They were divided \\
equally into two groups. The group I ( $n=20)$ consisted of patients undergoing Herniotomy and group II \\
(n=20) were undergoing Herniorrhaphy. The patients presented with symptoms of swelling in the inguinal \\
region with or without pain in the area of varying durations. The patients underwent standardized \\
operative procedures based on the group of the study. The patients were monitored carefully for any \\
complication. Patients were discharged when they were considered fit to go home. Follow up done for \\
every month for 3 months and then once in 6 months. \\
Results: The mean of Group I was 27.5 years and the mean age Group II was 25.5 years. In both, the \\
groups out of total n=40 patients $n=23(57.5 \%)$ were with right side involvement. $10 \%$ of patients were \\
found to have a bilateral hernia in both the group I and II. The common post-operative complication seen \\
in both the groups was postoperative pain in $10 \%$ of patients in group I and $15 \%$ of patients in group II. \\
Chronic orchalgia was the commonly found complication and it was present in $5 \%$ of patients of group I \\
and $15 \%$ of patients with group II. \\
Conclusion: we concluded that the right side indirect inguinal hernia is very common in young adult \\
males. It was found that herniotomy had advantages like a lesser duration of hospital stay, lesser \\
incidences of postoperative complications. Therefore small hernia in young adults with good abdominal \\
tone herniotomy may the preferred choice of treatment for indirect inguinal hernia. \\
Keywords: Herniotomy, Herniorrhaphy, uncomplicated Indirect Inguinal Hernia. \\
\hline
\end{tabular}

\section{Introduction}

A hernia is defined as an abnormal protrusion of a portion of an organ or tissue through a defect in the cavity containing it. Indirect inguinal hernias occur when the abdominal contents protrude through deep inguinal ring lateral to the inferior epigastric vessels. The contents can also descend along with the inguinal sac to the scrotum through 
the superficial inguinal ring it occurs due to the failure of embryonic closure of processus viganalis. Inguinal hernias constitute about $75 \%$ of all abdominal wall hernias, the lifetime risk in males is $27 \%$ and females are $3 \%{ }^{[1]}$. Repair of inguinal hernia is the commonest operation performed by the General Surgeon worldwide ${ }^{[2-4]}$. An estimate has shown that more than 20 million inguinal hernias are repaired annually around the world; specific rates by country vary from 100 to 300 per 100,000 populations per year ${ }^{[5,6]}$. Inguinal hernias are more common in males with reports in the literature showing from M: F 3:1 to $14: 1^{[7-9]}$. Direct Inguinal hernias in children can also occur due to weakness of the floor of the inguinal canal or secondary to surgical correction of indirect inguinal hernia. It is important to detect the type of inguinal hernia in each patient clinically to choose a suitable type of surgery. Herniotomy whether open or laparoscopic is the gold standard for the treatment of indirect hernias in young adults. Many indirect inguinal hernias are treated with herniorrhaphy or hernioplasty for treating young adults with indirect inguinal hernia are still a matter of debate. Many studies have shown that herniorrhaphy generally increases the operation time, days of work, postoperative pain and overall costs of treatment also require greater surgical skills to perform. To overcome it many advocate Herniotomy which is performed as daycare surgery with small-time for the hospital stay and low risk of complications in herniotomy. With this background, we in the present study tried to evaluate the outcome of herniotomy and herniorrhaphy for the treatment of indirect inguinal hernias in young adult males and compared the overall outcome of treatment in terms of complications for the patients detected with an inguinal hernia in our tertiary care hospital.

\section{Material and Methods}

The present cross-sectional comparative study was carried in the Department of General Surgery, Rajiv Gandhi Institute of Medical Sciences
[RIMS] Adilabad. Institutional Ethical committee permission was obtained for the study. Written consent was obtained from all the participants of the study after explaining the nature of the study in the local language. The inclusion criteria were adult patients up to 35 years with a good abdominal tone, patients were selected with a small hernia (bubonocele), patients with Nyhus I hernia. Exclusion criteria were patients with a direct hernia, obstructed or strangulated hernia, previous abdominal surgeries, lax abdomen, obesity, not within the age groups. Based on the inclusion and exclusion criteria during the study period, we identified a total of $n=40$ patients. They were divided equally into two groups. The group I $(n=20)$ consisted of patients undergoing Herniotomy and group II $(\mathrm{n}=20)$ were undergoing Herniorrhaphy. The patients presented with symptoms of swelling in the inguinal region with or without pain in the area of varying durations. The patients were examined for direct or indirect uncomplicated inguinal hernia. A detailed history was obtained and a thorough physical examination was done including general, systemic and local examination. The patients were subjected to various investigations which included CBP, BT\&CT, FBS, serum urea and creatinine, urine for albumin, microscopy, and sugar. ECG, CXR for any lung pathology, USG was done to rule benign enlargement of the prostate. All the patients were given pre-operative antibiotic cefotaxime $1 \mathrm{gm} \mathrm{IV}$. Spinal/local anesthesia was administered for herniotomy an oblique incision was made parallel to the inguinal ligament at 1.5 $\mathrm{cm}$ above the ligament. The incision was deepened to expose the external oblique aponeurosis. The external oblique aponeurosis is divided up to the external ring. Cord structures are freed by blunt dissection from the inferior flap. The cremasteric box is opened to expose the sac. The sac is freed till the deep ring after emptying its contents and it is transfixed, ligated and excised. The wound closure is done in layers. For herniorrhaphy following similar initial steps of herniotomy the weakened posterior inguinal wall 
was repaired by Bassini's Technique where reconstruction of the posterior wall is done by suturing transversalis fascia, transverses abdominis muscle and internal oblique muscle (Bassini's triple-layer) to the inguinal ligament ${ }^{[11]}$. In the post-operative period Inj Diclofinac 1$2 \mathrm{mg} / \mathrm{Kg}$ body wt IM BD was administered for 48 hours and Inj Cefotaxime 1gm IV BD was also continued for 48 hours. The patients were monitored carefully for any complication. All the postoperative complications were noted. Patients were discharged when they were considered fit to go home. Sutures were removed on the $7^{\text {th }}$ postoperative day. Follow up done for every month for 3 months and then once in 6 months.

\section{Results}

In the present study, $n=40$ male patients were selected undergoing out of which $n=20$ underwent herniotomy and $n=20$ patients underwent herniorrhaphy. The majority of patients $n=10$ $(50 \%)$ in group I herniotomy were belonging to 26 to 30 years. In group II out of $n=20$ patients, $n=12$ $(60 \%)$ were belonging to $26-30$ years of age group. Hence in both the group age group $26-30$ years represented the age for the presentation of indirect inguinal hernia. The mean of Group I was 27.5 years and the mean age Group II was 25.5 years. The other characteristics are given in table 1.

Table 1: showing the Demographic profile of patients involved in the study

\begin{tabular}{|l|c|c|c|c|c|c|}
\hline \multirow{2}{*}{$\begin{array}{c}\text { Age group } \\
\text { in years }\end{array}$} & \multicolumn{2}{|c|}{ Group I [Herniotomy] } & \multicolumn{2}{c|}{ Group II [Herniorrhaphy] } & Total & percentage \\
\hline Number (N) & Percentage & Number (N) & Percentage & & \\
\hline $\mathbf{1 5 - 2 0}$ & 2 & 10 & 3 & 15 & 05 & 12.5 \\
\hline $\mathbf{2 1}-\mathbf{2 5}$ & 6 & 30 & 5 & 25 & 11 & 27.5 \\
\hline $\mathbf{2 6 - 3 0}$ & 10 & 50 & 12 & 60 & 12 & 30 \\
\hline $\mathbf{3 1 - 3 5}$ & 2 & 10 & 0 & 00 & 02 & 5 \\
\hline Total & 20 & 100 & 20 & 100 & 40 & 100 \\
\hline
\end{tabular}

The right side appeared to be commonly involved in the indirect inguinal hernia. In group I, $60 \%$ of patients were found with right side inguinal hernia. In group II 55\% of the patients were found with right sides inguinal hernia. In both, the groups out of total $n=40$ patients $n=23(57.5 \%)$ were with right side involvement. $10 \%$ of patients were found to have a bilateral hernia in both the group I and II shown in table 2.

Table 2: Showing the involved sides in the cases of indirect inguinal hernia

\begin{tabular}{|l|c|c|c|c|c|c|}
\hline \multirow{2}{*}{ side } & \multicolumn{2}{|c|}{ Group I [Herniotomy] } & \multicolumn{2}{c|}{ Group II [Herniorrhaphy] } & \multirow{2}{*}{ Total } & \multirow{2}{*}{ Percentage } \\
\cline { 2 - 5 } & Frequency & Percentage & Frequency & Percentage & & \\
\hline Right & 12 & 60 & 11 & 55 & 23 & 57.5 \\
\hline Left & 6 & 30 & 7 & 35 & 13 & 32.5 \\
\hline Bilateral & 2 & 10 & 2 & 10 & 04 & 10 \\
\hline Total & 20 & 100 & 20 & 100 & 40 & 100 \\
\hline
\end{tabular}

The mean duration of hospital stay was recorded in both the group of patients. In the group, I, the mean duration of hospital stay was 6.5 days and in group II it was 8.2 days. The early postoperative complications encountered in group II were $35 \%$ as compared to group I $20 \%$. The common post- operative complication seen in both groups was post-operative pain. It was found with $10 \%$ of patients in group I and $15 \%$ of patients in group II. The rate of infections was 5\% in group I and $10 \%$ in group II shown in table 3. 
Graph 1: predominant signs and symptoms of patients in both groups

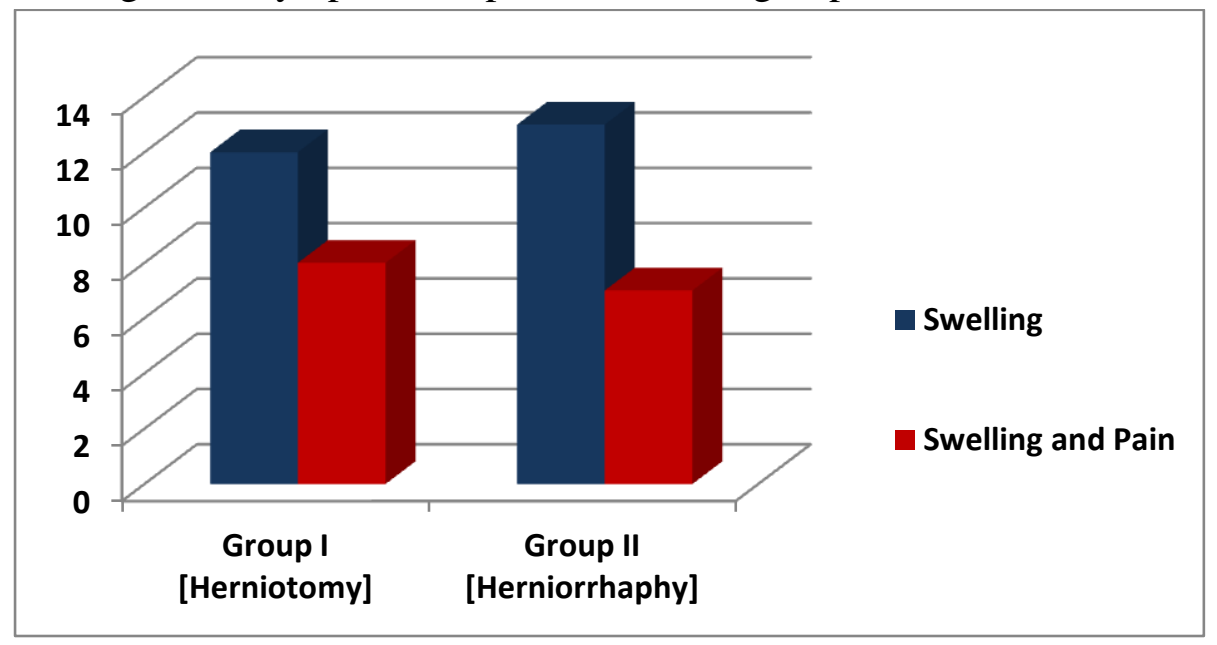

Table 3: Showing the early postoperative complications recorded in the study

\begin{tabular}{|l|c|c|c|c|}
\hline \multirow{2}{*}{ Early postoperative Complications } & \multicolumn{2}{|c|}{ Group I [Herniotomy] } & \multicolumn{2}{c|}{ Group II [Herniorrhaphy] } \\
\cline { 2 - 5 } & Frequency & Percentage & Frequency & Percentage \\
\hline Infection/abscess & 1 & 5 & 2 & 10 \\
\hline Hematoma & 1 & 5 & 0 & 0 \\
\hline Seroma & 0 & 0 & 1 & 5 \\
\hline Post-operative Pain & 2 & 10 & 3 & 15 \\
\hline Hydrocele/Hematocele & 0 & 0 & 1 & 5 \\
\hline Total & 4 & 20 & 7 & 35 \\
\hline
\end{tabular}

Late complications were noticed in $10 \%$ of patients of group I and 35\% of patients in group II Chronic orchalgia was the commonly found complication and it was present in $5 \%$ of patients of group I and $15 \%$ of patients with group II. It indicates that the patients undergoing herniorrhaphy are more likely to develop chronic orchalgia complications. Recurrence was also found more in group II as compared to group I the other complications are described in table 4.

Table 4: showing the late postoperative complications in the study

\begin{tabular}{|l|c|c|c|c|}
\hline \multirow{2}{*}{ Late postoperative Complications } & \multicolumn{2}{|c|}{ Group I [Herniotomy] } & \multicolumn{2}{c|}{ Group II [Herniorrhaphy] } \\
\cline { 2 - 5 } & Frequency & Percentage & Frequency & Percentage \\
\hline Recurrence & 0 & 0 & 2 & 10 \\
\hline Ischemic Orchitis & 0 & 0 & 1 & 5 \\
\hline Testicular atrophy & 1 & 5 & 1 & 5 \\
\hline Chronic Orchalgia & 1 & 5 & 3 & 15 \\
\hline Total & 2 & 10 & 7 & 35 \\
\hline
\end{tabular}

\section{Discussion}

Inguinal hernia repairs spend an important part of health care assets because of the high incidence of the problem. Surgical treatment is done in the majority of cases and often successful but recurrences occur in 10-15\% of cases and long term disability due to chronic pain occurs in about $10-12 \%$ of patients ${ }^{[12]}$. The surgical repair of indirect inguinal hernia in young adults is still a controversial topic. Some advocate hernioplasty instead of herniotomy to prophylactically repair the posterior wall of the inguinal canal to encounter difficulty in the future if recurrence or new hernia occurs after surgical repair. This study aimed to evaluate the outcomes of herniotomy and herniorrhaphy. In the present study, the mean age of Group I was 27.5 years and the mean age of Group II was 25.5 years. The commonest presentation of hernia cases in the present study was swelling in $62.5 \%$ of cases. There were 
swelling and pain present in $37.5 \%$ of cases. A study by A Hair et al; have found $66 \%$ of patients presented with swelling and pain ${ }^{[13]}$. The differences could be due to a difference in the pain threshold of individuals. In the present study right side was involved in indirect inguinal hernia in $57.5 \%$ of cases. The right side appeared to be commonly involved in the indirect inguinal hernia and is predominantly indirect or inguinoscrotal. The number of cases of the bilateral presentation was $n=4(10 \%)$, which supports that some hernias are having a congenital basis. They appear early in life and present as inguinoscrotal hernias. In group I, $60 \%$ of patients were found with right side inguinal hernia. The embryological origin and descent of testis explain the right side predominance. The right testis descends later than the left and hence higher incidence of patent processes viginalis on right is side is present ${ }^{[14]}$. Most of the clinical cases of hernias are indirect hernia hence these cases were utilized for the results of the present study ${ }^{[15,16]}$. The incidence of postoperative infection in the current study was $10 \%$ and the pain was found in $15 \%$ of the patients. It was also found that patients undergoing herniorrhaphy were having a greater degree of pain as compared to herniotomy patients on pain scales. The postoperative analgesic requirements of group II were significantly greater as compared to group I. In the present study the postoperative infection rate was found to be $5 \%$ in herniotomy group and $10 \%$ in herniorrhaphy group. The other complication was the presence of hematoma in one patient of group I seroma in group II. In a similar study conducted on 1369 patients in Jaipur with a follow of 1340 subjects for a period of ten years revealed except minor scrotal hematoma no other complication was seen. The incidence of recurrence was found in $0.15 \%$ of cases ${ }^{[17]}$. In the present study, late complications like recurrence were found in 2 cases of group II and testicular atrophy in one case of group II. A retrospective analysis of late complications with a mean follows up period of 13.2 years in 837 cases of interventions including herniotomy and Bassini's herniorrhaphy found the overall recurrence rate of $10.5 \%$ and cumulative recurrence of $26 \%$ in two years. Testicular atrophy was seen in $1.2 \%$ of cases and chronic pain and entrapment in $2.9 \%$ of cases. A recurrence rate of $23 \%$ was reported which is independent of age, sex type of hernia or technique of operation ${ }^{[18]}$. Although the true incidence of hernia can be known in long term follow up of 4-5 years we could not do it because of time constraints and patient factors.

\section{Conclusion}

In this study, we concluded that the right side indirect inguinal hernia is very common in young adult males. It was found that herniotomy had advantages like a lesser duration of hospital stay, lesser incidences of postoperative complications. Therefore small hernia in young adults with good abdominal tone herniotomy may the preferred choice of treatment for indirect inguinal hernia.

\section{Conflict of interest: None \\ Source of Support: Nil \\ Ethical Permission: Obtained}

\section{References}

1. John $\mathrm{T}$ Jenkins, Patrick $\mathrm{J} O$ Dwyer. Inguinal Hernias. British Medical Journal 2008; 336(7638): 269-72.

2. Kulacoglu H. Current options in inguinal hernia repair in adult patients. Hippokratia 2011; 15 (3): 223 - 31.

3. Oribabor FO, Amao OA, Akanni OS, and Fatidinu SO. The use of nontreated mosquito net mesh cloth for a tension-free inguinal hernia repair: Our experience. Nig J Surg 2015; 21 (1): 48 - 51.

4. Adesunkanmi ARK, Badmus TA and Ogundoyin O. Determinants of the outcome of inguinal herniorrhaphy in Nigerian patients. Ann Coll Surg H K 2004; 8: $14-21$.

5. Ohene-Yeboah $M$ and Abatanga $F$. Inguinal hernia disease in Africa: A 
common, but neglected surgical condition. West Afr J Med 2011; 30 (2): 77 - 83.

6. Bay - Nielsen M, Kehlet H, Strand L, Malmastrǿm J, Andersen F, Wara P, et al. Quality assessment of 26,304 herniorrhaphies in Denmark: A prospective nationwide study. Lancet 2001; 258: $1124-28$.

7. Zendejas B, Ramirez $\mathrm{T}$, Jones $\mathrm{T}$, et al. Incidence of inguinal hernia repairs in Olmsted County, MN. Ann Surg. 2013;257(3):520-26.

8. Burcharth J, Pedersen M, Bisgaard T, Pedersen C, Rosenberg J. Nationwide prevalence of groin hernia repair. PLoS One. 2013;8(1):e54367.

9. Rosen A, Nathan H, Luciansky EOR. The inguinal region: anatomic differences in men and women with reference to hernia formation. Acta Anat. 1989; 136(4):30610.

10. PJ Vincent, Y Singh VSM, Modern management of Inguinal Hernia. Med J Armed Forces India 2000;56(4):323-27.

11. Castrini G, Pappalardo G, Trentino P, et al; The original Bassini's Technique in surgical treatment of inguinal hernia. Int Surgery 1986; 71:41.

12. Sevonius D, Gunnarsson U, Nordin P, Nilsson E, Sandblom G. Recurrent groin hernia surgery. Br J Surg 2011; 98(10):1489-94.

13. Alan Hair. What effect does the duration of inguinal hernia have on patient symptoms? Journal of the American College of surgery2001; 193:125-29.

14. Luciano A. Favorito, Helce Riberio JulioJunior, and Francisco J. Sampaio Relationship between undescended Testis Position and prevalence of testicular appendices, epididymal anomalies, and Patency of Processus Vaginalis. BioMed Research International volume 2017; 1-6.
15. Palanivelu C. Result of hand sutured laparoscopic hernioplasty: an effective method of repair. Indian Journal of Surgery 2000;62(5):339-41.

16. Robb H Ruthledge. Cooper's ligament repair. A 35 years experience with a single technique for all groin hernias in adults. British J of Surg 1988; 103(1):1-10.

17. Sarin YK, Wakhlu A, Agrawal LD, Sharma AK. Inguinal herniotomy in children: a decade's experience. J Ind Paed. 1993;30(11):1363-66.

18. Herzog U. Late results following inguinal or femoral hernia surgery. Langenbecks Arch Chir 1990; 375(1):5-10. [Article in German]. 